\title{
A transwell assay that excludes exosomes for assessment of tunneling nanotube- mediated intercellular communication
}

\author{
Venugopal Thayanithy ${ }^{1,6}$, Patrick O'Hare ${ }^{1}$, Phillip Wong ${ }^{1}$, Xianda Zhao ${ }^{2}$, Clifford J. Steer ${ }^{3,4}$, Subbaya Subramanian ${ }^{2}$ \\ and Emil Lou ${ }^{1,5^{*}}$
}

\begin{abstract}
Background: Tunneling nanotubes (TNTs) are naturally-occurring filamentous actin-based membranous extensions that form across a wide spectrum of mammalian cell types to facilitate long-range intercellular communication. Valid assays are needed to accurately assess the downstream effects of TNT-mediated transfer of cellular signals in vitro. We recently reported a modified transwell assay system designed to test the effects of intercellular transfer of a therapeutic oncolytic virus, and viral-activated drugs, between cells via TNTs. The objective of the current study was to demonstrate validation of this in vitro approach as a new method for effectively excluding diffusible forms of long- and close-range intercellular transfer of intracytoplasmic cargo, including exosomes/microvesicles and gap junctions in order to isolate TNT-selective cell communication.
\end{abstract}

Methods: We designed several steps to effectively reduce or eliminate diffusion and long-range transfer via these extracellular vesicles, and used Nanoparticle Tracking Analysis to quantify exosomes following implementation of these steps.

Results: The experimental approach outlined here effectively reduced exosome trafficking by $>95 \%$; further use of heparin to block exosome uptake by putative recipient cells further impeded transfer of these extracellular vesicles.

Conclusions: This validated assay incorporates several steps that can be taken to quantifiably control for extracellular vesicles in order to perform studies focused on TNT-selective communication.

Keywords: Tunneling nanotubes, Membrane nanotubes, Intercellular transfer, Intercellular communication, Transwell assay, Exosomes, Microvesicles, Extracellular vesicles

\section{Background}

Intercellular communication is an important biological process that was originally thought to occur exclusively via cytokine, chemokine, hormone, and growth factor signaling, in addition to intercellular transfer of signals via gap junctions. During the past decade, the discovery of exosomes, microvesicles (MV), and long actin-based membranous cellular extensions termed "tunneling nanotubes"

\footnotetext{
* Correspondence: emil-lou@umn.edu

'Department of Medicine, Division of Hematology, Oncology and

Transplantation, University of Minnesota, Mayo Mail Code 480, 420 Delaware

Street SE, Minneapolis, MN 55455, USA

${ }^{5}$ Graduate Faculty, Department of Integrative Biology and Physiology,

University of Minnesota, Minneapolis, MN 55455, USA

Full list of author information is available at the end of the article
}

(TNTs) has significantly expanded the repertoire of known mediators of intercellular signaling.

TNTs are structures that can extend up to several hundreds of microns between cells to provide direct conduits of communication. The width of TNTs can range from 50 to $1000 \mathrm{~nm}$, and their length ranges from a few to several hundred microns. Several dozen published studies have incorporated use of transwell assays to study effects of long-distance intercellular communication, either by TNTs or by exosomes/microvesicles [1-26] (summarized in Tables 1 and 2). However, the results of these studies have been difficult to interpret for several reasons. First, many of these studies assumed that TNTs are not capable of traversing the membrane filter and facilitating intercellular transfer between 
Table 1 Published studies using transwell membranes for investigation of cell contact-dependent intercellular transfer

\begin{tabular}{|c|c|c|c|c|}
\hline Purpose of experiment & $\begin{array}{l}\text { Pore size of the } \\
\text { transwell filter }\end{array}$ & Reference & $\begin{array}{l}\text { Effect of the } \\
\text { transwell filter }\end{array}$ & Observations/Conclusions \\
\hline $\begin{array}{l}\text { Transfer of HIV-1 virions between } \\
\text { Jurkat T cells }\end{array}$ & $3000 \mathrm{~nm}$ & [14] Sowinski et al., 2008 & Negative & Decreased HIV-1 transfer \\
\hline $\begin{array}{l}\text { Transfer of apoptotic signal from } \\
\text { stromal cells to B cells }\end{array}$ & $3000 \mathrm{~nm}$ & [15] Teague et al., 2010 & Negative & Cell contact was necessary for transfer \\
\hline $\begin{array}{l}\text { Transfer of miRNAs between cancer } \\
\text { and endothelial cells }\end{array}$ & $\begin{array}{l}3000 \mathrm{~nm} \& \\
400 \mathrm{~nm}\end{array}$ & [2] Connor et al., 2015 & Negative & $\begin{array}{l}\text { Transfer of miRNA was reduced to } \\
\text { basal levels }\end{array}$ \\
\hline $\begin{array}{l}\text { Lysosomes mediated transfer of } \\
\text { cystinosin \& cystinebetween mouse } \\
\text { fibroblasts and macrophages }\end{array}$ & $1000 \mathrm{~nm}$ & [7] Naphade et al., 2015 & Negative & Decreased cysteine transfer \\
\hline $\begin{array}{l}\text { Transfer of DiD between NRK, CHO } \\
\text { and HeLa cells }\end{array}$ & $450 \mathrm{~nm}$ & [13] Schoelermann et al., 2015 & Negative & Transfer of DiD was reduced \\
\hline $\begin{array}{l}\text { Transfer of CD4OL-induced cytoplasmic } \\
\text { and cell surface-associated material } \\
\text { from T cells to dendritic cells }\end{array}$ & $450 \mathrm{~nm}$ & [17] Zaccard et al., 2014 & Negative & Decrease in transfer \\
\hline $\begin{array}{l}\text { Transfer of prion particles between } \\
\text { mouse neuronal cells }\end{array}$ & $400 \mathrm{~nm}$ & [4] Gousset et al., 2009 & Negative & Prion transfer was entirely abolished \\
\hline $\begin{array}{l}\text { Transfer of cues for cell migration } \\
\text { from endothelial cells to bronchial } \\
\text { epithelial cells }\end{array}$ & $400 \mathrm{~nm}$ & [18] Zani et al., 2010 & Negative & $\begin{array}{l}\text { Bronchial epithelial cell migration } \\
\text { required direct cell contact with } \\
\text { endothelial cells }\end{array}$ \\
\hline $\begin{array}{l}\text { Transfer of prion particles in mouse } \\
\text { neuronal cells }\end{array}$ & $400 \mathrm{~nm}$ & [5] Langevin et al., 2010 & Negative & Prion transfer was reduced over $98 \%$ \\
\hline $\begin{array}{l}\text { Transfer of mitochondria from } \\
\text { vascular smooth muscle cells to } \\
\text { mesenchymal cells }\end{array}$ & $400 \mathrm{~nm}$ & [16] Vallabhaneni et al., 2012 & Negative & $\begin{array}{l}\text { Direct cell contact was required for } \\
\text { mitochondrial transfer }\end{array}$ \\
\hline $\begin{array}{l}\text { Transfer of p-glycoprotein between } \\
\text { MCF-7 breast cancer cells }\end{array}$ & $400 \mathrm{~nm}$ & [42] Pasquier et al., 2012 & Negative & Reduced p-glycoprotein transfer \\
\hline $\begin{array}{l}\text { Transfer of Huntington mutant } \\
\text { protein }(\mathrm{Htt}) \text { aggregates in } \\
\text { mouse neuronal cells }\end{array}$ & $400 \mathrm{~nm}$ & [3] Costanzo et al., 2013 & Negative & $\begin{array}{l}\text { Htt aggregate transfer was blocked } \\
\text { by over } 95 \%\end{array}$ \\
\hline $\begin{array}{l}\text { Transfer of contact dependent } \\
\text { proliferation cues from astrocytes } \\
\text { to glioma cells }\end{array}$ & $400 \mathrm{~nm}$ & [19] Zhang and Zhang, 2015 & Negative & Decreased transfer of molecular cues \\
\hline $\begin{array}{l}\text { Transfer of mCherry from senescent } \\
\text { cells to NK cells }\end{array}$ & $400 \mathrm{~nm}$ & [1] Biran et al., 2015 & Negative & mCherry transfer was reduced \\
\hline $\begin{array}{l}\text { Transfer of soluble amino acids } \\
\text { between bacterial cells }\end{array}$ & $200 \mathrm{~nm}$ & [9] Pande et al., 2015 & Negative & $\begin{array}{l}\text { Amino acid transfer was entirely } \\
\text { blocked }\end{array}$ \\
\hline $\begin{array}{l}\text { Mitochondrial transfer in MDA-MB231, } \\
\text { OVCAR3, SKOV3 and MCF-7 cells }\end{array}$ & NA & [42] Pasquier et al., 2013 & Negative & Decrease in mitochondrial transfer \\
\hline
\end{tabular}

These experiments used transwell membrane filters with a range of pore sizes to separate two populations of cells, in order to demonstrate cellular transfer that was dependent on cell contact by any means (including TNTs)

separated cell populations. Thus they used standard transwell/Boyden chamber assays as negative controls with the intent of demonstrating lack of TNT communication. Second, and conversely, protocols that applied the same in vitro system to evaluate TNT-mediated transfer did not include specific measures to identify the effects of exosomes and microvesicles (herewith referred to collectively as extracellular vesicles, or EVs) from the effects of TNTs. Identification and validation of such an assay is imperative in moving this field of cell communication forward. We postulated that adding a series of steps to modify the standard transwell assay would effectively reduce or even eliminate intercellular trafficking of EVs, and thus negate any potential downstream effects of these EVs that could confound investigation of the effects of TNT-mediated transport.

\section{Methods}

\section{Cell lines and culture medium}

MSTO-211H (MSTO) is derived from a patient with biphasic mesothelioma (ATCC no. CRL-2081). VAMT is a sarcomatoid mesothelioma cell line. Both cell lines were obtained courtesy of Dr. Yuman Fong, Memorial SloanKettering Cancer Center. All cell lines were passaged in plasmocin-containing medium (Invivogen, San Diego, $\mathrm{CA})$ and tested negative for mycoplasma contamination. 
Table 2 Published studies using transwell assays to investigate EV-specific intercellular transfer

\begin{tabular}{|c|c|c|c|c|}
\hline Purpose of experiment & $\begin{array}{l}\text { Pore size of the } \\
\text { transwell filter }\end{array}$ & Reference & $\begin{array}{l}\text { Effect of the } \\
\text { transwell filter } \\
\text { on EV transfer }\end{array}$ & Observations/Conclusions \\
\hline $\begin{array}{l}\text { Transfer P-glycoprotein between cells from } \\
\text { human bladder cancer cell line BIU-87 }\end{array}$ & $3000 \mathrm{~nm}$ & [26] Zhou et al., 2013 & Neutral & $\begin{array}{l}\text { Transfer was not affected; p-glycoprotein } \\
\text { transfer does not require direct cell-to-cell } \\
\text { contact }\end{array}$ \\
\hline $\begin{array}{l}\text { Transfer of HIV-1 viral particles between } \\
\text { T cells }\end{array}$ & $3000 \mathrm{~nm}$ & [6] Martin et al., 2010 & Neutral & Transwell filter allowed HIV-1 viral transfer \\
\hline $\begin{array}{l}\text { Transfer of exosomes from oligodendrocyte } \\
\text { to primary cortical neurons }\end{array}$ & $1000 \mathrm{~nm}$ & [46] Fruhbeis et al., 2013 & Neutral & Transwell filter allowed exosome transfer \\
\hline $\begin{array}{l}\text { Exosome-mediated transfer of EBV-encoded } \\
\text { small RNAs between lymphoblasts and } \\
\text { dendritic cells }\end{array}$ & $\begin{array}{l}1000 \& \\
400 \mathrm{~nm}\end{array}$ & [20] Zomer et al., 2010 & Negative & Decreased small RNA transfer \\
\hline $\begin{array}{l}\text { Transfer of membrane proteins between } \\
\text { Chinese hamster ovary (CHO) cells in culture } \\
\text { as well as via } 200 \mathrm{~nm} \text { filtered culture media }\end{array}$ & $\begin{array}{l}450 \mathrm{~nm} \& \\
200 \mathrm{~nm}\end{array}$ & [8] Niu et al., 2008 & Negative & Reduced transfer of membrane proteins \\
\hline $\begin{array}{l}\text { Exosome-mediated transfer of Cy3-labeled } \\
\text { microRNAs from leukemia cells to } \\
\text { endothelial cells }\end{array}$ & $450 \mathrm{~nm}$ & [25] Umezu et al., 2013 & Neutral & $\begin{array}{l}\text { Transwell filter allowed transfer of } \\
\text { miRNAs }\end{array}$ \\
\hline $\begin{array}{l}\text { Exosome-mediated transfer of Cy3-labeled } \\
\text { synthetic } 22 \text { bp miRNA, from Burkitt } \\
\text { lymphoma B cells to T cells }\end{array}$ & $400 \mathrm{~nm}$ & [12] Rechavi et al., 2009 & Negative & miRNA transfer was reduced \\
\hline $\begin{array}{l}\text { Transfer of TGF } \beta-1 \text { from platelets to colon } \\
\text { and breast carcinoma cells }\end{array}$ & $400 \mathrm{~nm}$ & [23] Labelle et al., 2011 & Neutral & Transwell filter allowed transfer \\
\hline $\begin{array}{l}\text { Exosome-mediated transfer of G-protein } \\
\text { coupled receptors in U87MG, COS-7 or } \\
\text { HEK293T cells }\end{array}$ & $400 \mathrm{~nm}$ & [21] Guescini et al., 2012 & Neutral & Transwell filter allowed TGF $\beta-1$ transfer \\
\hline $\begin{array}{l}\text { Transfer of anti-miR-9 from MSCs to } \\
\text { glioblastoma cells }\end{array}$ & $400 \mathrm{~nm}$ & [24] Munoz et al., 2013 & Negative & Transfer was reduced from $90 \%$ to $16 \%$ \\
\hline $\begin{array}{l}\text { Transfer of secretory factors from } \\
\text { mesenchymal stem cells to nucleus } \\
\text { pulposus cells }\end{array}$ & $400 \mathrm{~nm}$ & [22] Hu et al., 2015 & Neutral & $\begin{array}{l}\text { Transwell filter allowed transfer of } \\
\text { secretory factors }\end{array}$ \\
\hline
\end{tabular}

Cell lines MSTO-211H and VAMT were authenticated by the Core Fragment Analysis Facility at Johns Hopkins University using short tandem repeat profiling. All cells were passaged using 10\% fetal calf serum (FCS) in RPMI-1640 with $25 \mathrm{mM}$ glucose, supplemented with $1 \%$ penicillin-streptomycin (P-S) and 2\% L-glutamine, at normal $\mathrm{pH}$ (7.6). To stimulate nanotube formation for in vitro examination, cells were grown in $2.5 \%$ FCS in RPMI-1640 containing $50 \mathrm{mM}$ glucose, supplemented with $1 \%$ P-S, $2 \%$ L-glutamine with or without $10 \mathrm{mM}$ ammonium lactate (Sigma Aldrich, St. Louis, Missouri) and acidification of medium to $\mathrm{pH} 6.6$, per our prior study [27]. All cultures were done in $75 \mathrm{~cm}^{2}$ tissue culture flasks (Falcon, Becton Dickson, Oxnard, CA) at $37{ }^{\circ} \mathrm{C}$ in $5 \% \mathrm{CO}_{2}$.

Imaging of TNTs traversing the polyester membrane filter (modified transwell assay)

MSTO-211H cells were primed in TNT medium for 3 days, after which TNT culture medium was removed and replaced with serum-free mTeSR media containing pituitary bovine extract for 24 more hours. Cells were harvested by trypsinization, washed and stained with fluorescent DiI for $15 \mathrm{~min}$ at $37{ }^{\circ} \mathrm{C}$, following standard protocols (Life Technologies, Carlsbad, CA). $8.0 \times 10^{5}$ DiI-stained MSTO cells were placed in the upper chamber of transwell assays containing inserts with $0.4 \mu \mathrm{m}$ diameter pores, and incubated for $48 \mathrm{~h}$. Of note, the transwell insert consists of a polyester membrane $10.0 \mu \mathrm{m}$ thick and contains $\sim 4 \times 10^{6}$ pores $/ \mathrm{cm}^{2}$.

After $48 \mathrm{~h}$, culture medium was removed and cells were gently washed twice in ice cold phosphate buffered saline (PBS) and fixed in ice cold neutral buffered formalin (NBF) for $15 \mathrm{~min}$. The polyester membrane was cut from the transwell insert and transferred to a stainless steel mounting chamber (Attofluor cell chamber, Life Technologies, Carlsbad, CA) using two $25 \mathrm{~mm}$ round glass coverslips of $0.17 \mathrm{~mm}$ thickness (Warner Instruments, Hamden, CT). The membrane was mounted onto a glass slide with Fluorshield (Sigma-Aldrich, St. Louis, MO, catalog number F6182) and imaged on a Nikon A1RMP confocal microscope using a $25 \times$ waterimmersion lens at laser scanning confocal modality using $561 \mathrm{~nm}$ excitation and $595 \mathrm{~nm}$ emission. Since the membrane was $10 \mu \mathrm{m}$ in thickness, imaging data were collected for a total thickness of $30 \mu \mathrm{m}$ from the middle 
depth of the membrane. In order to map the spatial and temporal location of the cells on the transwell membrane precisely, we employed transmitted detection (TD). Transmitted images were acquired simultaneously along with confocal images in real time by collecting the signals that were transmitted through the sample using the same illumination beam. Images were analyzed with NIS elements AR software (Nikon, version 4.00.07).

\section{Isolation of exosomes}

Exosomes were isolated using the Total Exosome Isolation Kit following the manufacturer's protocol (Invitrogen, Carlsbad, CA, Catalog number 4478359) as previously described [28]. Briefly, VAMT cells were grown to confluence in T75 flasks using 5\% FCS RPMI for 3 days, and cells were washed with mTeSR1 basal medium (Stemcell Technologies, Vancouver, BC, Canada) 3 times and grown in mTeSR1 basal medium for 2 days prior to exosome isolation. Exosomes were isolated and purified by successive ultracentrifugation steps [29]. Media from VAMT cell cultures $(18 \mathrm{ml}$ each) were collected, and ( $9 \mathrm{ml}$ of each) was added to $15 \mathrm{ml}$ Beckman centrifuge tubes (Beckman Coulter, Brea, CA, catalog number 342082) and spun at $2000 \mathrm{x} \mathrm{g}$ for $30 \mathrm{~min}$ to remove cells and debris. Supernatant was transferred $(9 \mathrm{ml}$ each) into fresh $15 \mathrm{ml}$ centrifuge tubes, and $4.5 \mathrm{ml}$ of exosome isolation reagent was added and mixed by inverting the tube a few times. Exosomes were precipitated by incubating at $4{ }^{\circ} \mathrm{C}$ overnight and collected by centrifuging at $10,000 \mathrm{x} \mathrm{g}$ for $1.0 \mathrm{~h}$ at $4{ }^{\circ} \mathrm{C}$. Supernatant was carefully removed by aspiration. Exosomes were then resuspended in PBS, aliquoted in $100 \mu \mathrm{l}$ fractions, and stored at $-80{ }^{\circ} \mathrm{C}$ until use.

Preparation of cells, transwell membrane incubation, and exosome recovery for imaging of VAMT exosomes using cryo-electron microscopy

To assess the ability of exosomes to traverse the physical barrier of a transwell membrane with the smallest available pore size $(0.4 \mu \mathrm{m})$, we added VAMT-derived exosomes to MSTO cells adhering to the transwell membrane filter in the the top chamber, as follows:

\section{Preparation of MSTO cells}

MSTO cells were first grown in 10\% FBS RPMI-1640 medium for $24 \mathrm{~h}$. This medium was then removed, and adherent cells in the flasks were washed 3 times with serum-free/vesicle-free mTeSR medium. To minimize the effects of exosome secretion by MSTO cells, this medium was replaced with fresh $\mathrm{mTeSR}$ medium after $24 \mathrm{~h}$. Then, the MSTO cells $\left(0.3 \times 10^{6}\right)$ were trypsinized and seeded on to 6-well plates with fresh mTeSR medium in triplicates with or without the transwell inserts each containing the same number of cells. After overnight incubation, the medium was changed and cells were subjected to incubation with VAMT-derived exosomes $\left(0.3 \times 10^{6}\right)$.

\section{Transwell incubation}

To assess the ability of exosomes to traverse the physical barrier of a transwell membrane, MSTO cells were seeded on the smallest available pore size $(0.4 \mu \mathrm{m})$ overnight; once the cells adhered to the membrane, we then added VAMT-derived exosomes to the top chamber $\left(0.3 \times 10^{6}\right)$ for incubation over $48 \mathrm{~h}$.

\section{Exosome recovery}

After $48 \mathrm{~h}$, we collected the culture medium from the bottom wells in order to determine the amount of exosomes that could have passed through the membrane filter during the incubation period. The media collected from the bottom wells ( $6 \mathrm{ml}$ of media total, from 3 identical wells) with or without addition of exosomes were collected and subjected to exosome isolation [30]. Briefly, the media were transferred to $15 \mathrm{ml}$ Beckman tubes (Beckman Coulter, Indianapolis, IN; catalog number \#342082) and centrifuged at $2000 \mathrm{~g}$ for $30 \mathrm{~min}$ to sediment contaminating cells. Clean cell-free media $(6 \mathrm{ml}$ each) were transferred into fresh $15 \mathrm{ml}$ centrifuge tubes and $3 \mathrm{ml}$ of exosome isolation reagent was added (Invitrogen, Carlsbad, CA; catalog number 4478359) and mixed by inverting the tubes three times. Exosomes were precipitated by incubating the mix overnight at $4{ }^{\circ} \mathrm{C}$ and collected by centrifuge at $10,000 \mathrm{~g}$ for $1 \mathrm{~h}$ at $4{ }^{\circ} \mathrm{C}$. Supernatant was removed by aspiration and the exosome pellet was suspended in $100 \mu \mathrm{l}$ of PBS and stored at $-80{ }^{\circ} \mathrm{C}$ until use.

\section{Nanoparticle tracking analysis}

Nanoparticle tracking analysis (NTA) operates on the Stokes-Einstein relationship. In short, the phenomenon of size dependence of solute diffusivity of nanoparticles in Brownian motion in a liquid suspension is determined by size, temperature, and viscosity. Briefly, digital images of scattered light from single particles were recorded and plots of scattered light spots and their speed of motion were subjected to software-based analysis to determine the particle count and size distribution.

We used a NanoSight LM14 analyzer (Malvern, Worcestershire, UK), at the University of MinnesotaTwin Cities Nano Center. Samples were diluted in $1.0 \mathrm{ml}$ of PBS (viscosity $0.952-0.953 \mathrm{cP}$ ) viewed, background corrected, and subjected to analysis at standard conditions recommended by the manufacturer. Video micrographs of particles undergoing Brownian motion were captured for $60 \mathrm{~s}$ at $22{ }^{\circ} \mathrm{C}$ using a SCMOS camera from which particle size and distribution was analyzed at recommended settings using NTA software (version 3.0068). Each sample was run 5 times independently, 
and the average number of particles was included for comparison.

\section{Scanning electron microscopy of TNTs traversing the polyester membrane}

MSTO cells preconditioned in TNT media for 7 days were plated onto transwell inserts containing polyester membranes with $400 \mathrm{~nm}$ pores on a 6-well plate (Corning Life Sciences, Corning, NY, Costar product \#3450 clear) in regular RPMI-1640 media with 10\% FBS, with antibiotics at standard cell culture conditions. After $48 \mathrm{~h}$, medium was removed and the membrane was gently washed with ice cold PBS and fixed with 4\% PFA for $10 \mathrm{~min}$ and washed gently in ice cold PBS. In order to visualize TNTs traversing the membrane through the $400 \mathrm{~nm}$ pores, the opposite side of the transwell membrane was imaged. The membrane was sliced out and mounted on to the SEM stage exposing the bottom side of the membrane. In order to detect TNTs, the membrane was imaged in vacuum without any processing or staining on a Sigma 500 VP FESEM (Carl Zeiss Industrial Metrology, Maple Grove, MN).

\section{Staining of exosomes}

$1 \times 10^{8}$ exosomes were stained using $10 \mu \mathrm{l}$ of PKH26 red fluorescent dye in a total volume of $400 \mu \mathrm{l}$ at room temperature, as recommended by the vendor (SigmaAldrich, St Louis, MO). After 10 min staining was stopped by adding equal volume of $1 \%$ BSA, and exosomes were recovered as mentioned using total exosome isolation reagent (Invitrogen).

\section{Heparin treatment to decrease EV uptake by putative recipient cells in the bottom chamber}

MSTO cells were plated in glass-bottomed 6-well plates (MatTek Corporation, Ashland, MA) in cell culture passage medium (10\% FBS, RPMI-1640), and cells were allowed to settle overnight. Differences in exosomal uptake were investigated with or without pre-treating the cells with $10 \mu \mathrm{g} / \mathrm{ml}$ of heparin (Heparin sodium salt from porcine intestinal mucosa, Sigma-Aldrich, St Louis, MO) in PBS for 30 minutes [31]. Cells were washed in $2.0 \mathrm{ml}$ of passage medium, and exosomes (100 exosomes/cell) were added in $500 \mu \mathrm{l}$ fresh medium and allowed to coat the cells by gently tilting the plates three times, followed by 15 min incubation at $37^{\circ} \mathrm{C}$. Exosome-containing medium was removed, cells were washed with passage medium and then returned to the incubator with $2.0 \mathrm{ml}$ of passage culture medium. Exosome uptake was determined by fluorescent microscopic imaging after $24 \mathrm{~h}$. This experiment was performed in triplicate, and representative images were taken from each of the replicates for subsequent analysis. Distribution of fluorescent exosomes was further analyzed using ImageJ software (https://imagej.nih.gov/ij/download.html) to assess the Corrected Total Cell fluorescence (CTCF) of cells (TNT-positive and TNT-negative cells) using the following equation:

CTCF = Integrated Density - (Area of selected cell * Mean fluorescence of the background readings).

CTCF/area was calculated for 36 cells in the control group, and 72 cells in the heparin-treated group, and the results were averaged.

\section{Availability of materials and data}

The datasets generated during and/or analyzed during the current study are included in this published article (and its Additional files 1, 2, 3, 4 and 5), and also are available from the corresponding author on request.

\section{Results}

\section{Overview of modifications to the transwell assay for} assessing TNT-selective intercellular transfer

The use of a transwell assay comprising two culture chambers separated by a porous membrane filter helps to eliminate gap junction-mediated intercellular communication through physical separation (Additional file 1: Figure S1). However, the transwell membrane can still allow the diffusion of EVs between separated populations of cells. To develop a transwell assay that specifically isolates TNT-mediated intercellular communication, it was necessary to address several concerns to more thoroughly exclude EV transfer. First, serum commonly used in culture medium inherently contains exosomes; and when loading serum-containing media to the top well of the assay, these exosomes may be transmitted via normal diffusion to the bottom well. Second, cells themselves, prior to and following deposit into the top chamber, shed EVs, and by so, decreasing this shedding would make exosomal transfer to cells in the bottom chamber less likely. Third, commercially available transwell assays can be selected based on pore size within the membrane filter; and the pore sizes may be as large as 3 or $8 \mu \mathrm{m}$. A large pore size can easily permit trafficking of exosomes and larger MVs and microparticles. Larger pore size may also permit cell contorsion and movement from the top to the bottom chamber, giving a false sense of communication due to cell movement itself. The exosomes or other vesicles that cross the filter via the pores might be absorbed by those cells in the bottom chamber, confounding the interpretation of TNT-selective transfer between donor and recipient cells.

For this study, we used cells derived from human malignant pleural mesothelioma as a model system, as we have used these cells extensively in our previously published studies characterizing TNTs. MSTO- $211 \mathrm{H}$ (also referred to as MSTO) is representative of the biphasic histologic subtype of mesothelioma, and VAMT is derived from the sarcomatoid histologic subtype. These cell lines 
readily form TNTs in cell culture, and thus are optimal for characterizing these unique cell protrusions [27, 32, 33]. We have previously noted that TNT formation in MSTO and VAMT cells is upregulated in conditions of metabolic and physiological stress, such as a low-serum, hyperglycemic microenvironment [27]; actin is uniformly present throughout the length of these TNTs, and ezrin and ZO-1 localize at the bases of TNTs in these cells; MSTO TNTs facilitate intercellular transfer of molecular cargo such as mitochondria and Golgi vesicles [27, 34]; and formation of TNTs in these cells can be suppressed via inhibition of mTOR. In a subsequent study, we further characterized TNTs in mesothelioma using these specific cell lines, and found that the average rate of formation of TNTs varied based on histopathologic subtype; the average length of MSTO and VAMT TNTs diminished over time [32]; and gene expression profiling of MSTO cells revealed variable regulation of genes responsible for cell cycle regulation, invasion, migration, and metastasis when cells were pre-cultured in low-serum, hyperglycemic medium. We also discovered that exosomes derived from malignant mesothelioma cells induced upregulation of TNT formation between MSTO cells, and that material from these exosomes subsequently shuttled through these newly formed TNTs [30]. Thus, based on our extensive prior characterization of TNTs in MSTO and VAMT cells, we elected to use this model system to develop and examine our transwell assay, but with the idea that the assay could potentially be applied to other TNT-forming cell types (malignant and non-malignant alike) as well.

Visual evidence of TNT formation and passage through and past the transwell filter using confocal microscopic imaging Our group has investigated formation and function of TNTs in a range of malignant and non-malignant cell lines, including pleural mesothelioma [27, 30, 32]. We have previously shown that these cell lines, including MSTO-211H (herein referred to as MSTO), readily form TNTs. Moreover, formation of TNTs is quantitatively upregulated when culturing these cells in low-serum, hyperglycemic culture media [27]; thus culturing cells in this medium could 'prime' cells to form TNTs and facilitate effective in vitro study. For those reasons, we selected MSTO cells as a model system for evaluation in the current study. As a control, we cultured MSTO cells in 6-well plates to confirm growth and formation of TNTs, and to provide representative examples of TNTs imaged using both light as well as fluorescent microscopic imaging in open culture (Fig. 1). To demonstrate TNT formation in the modified assay visually, we imaged TNTs protruding from cells and through the membrane filter as proof-of-concept that nanotubes were indeed forming and aligning with the pores as they extended toward the bottom chamber (Additional file 1:
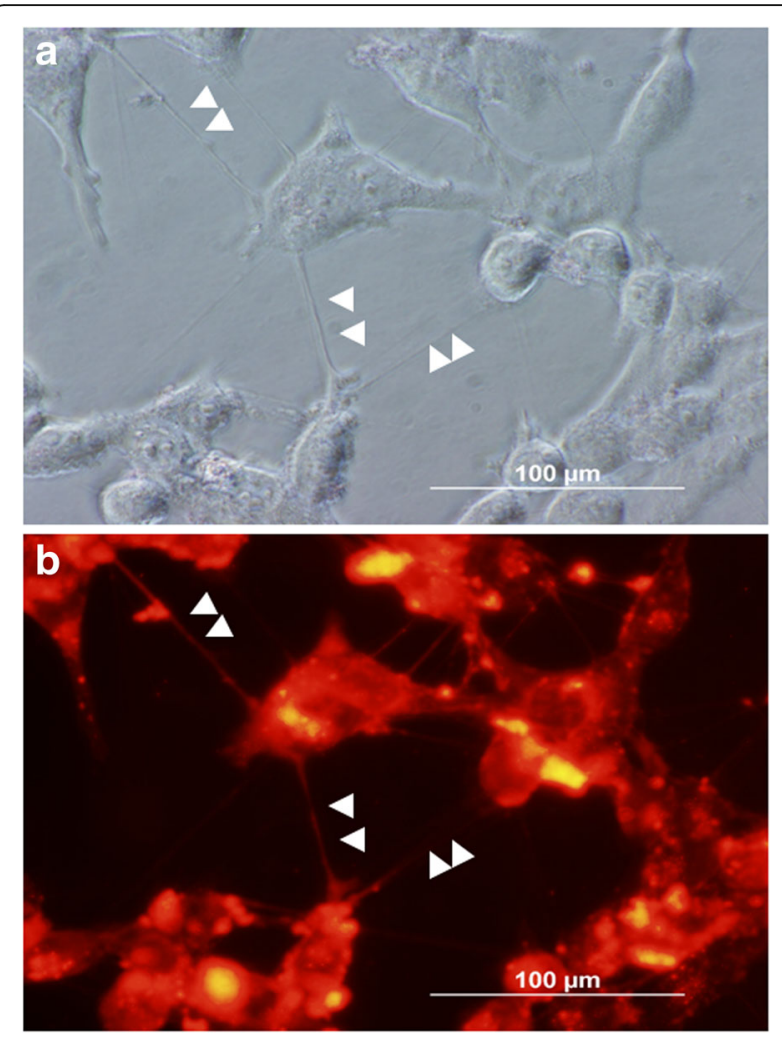

Fig. 1 Representative images of TNT formation of MSTO-211H malignant pleural mesothelioma cells in open culture (6-well standard culture plates). TNTs connecting Dil-stained MSTO cells are marked by white arrowheads. MSTO cells were first grown using standard passage medium (10\% FCS RPMI-1640), then switched to a low-serum, hyperglycemic RPMI-1640 culture medium, stained with lipophilic Dil, and imaged after $48 \mathrm{~h}$ on a Olympus X70 fluorescent microscope at $600 \times$ magnification using phase contrast (a) and fluorescent (b) settings

Figure S1 and Additional file 2: Figure S2). We removed and fixed the filter using paraformaldehyde and then performed confocal imaging. Three-dimensional confocal microscopy was performed to image TNTs in the z-plane (i.e. X-Z optical sectioned imaging), and y-planes (X-Y cross-sectional imaging for examination of depth). Here, we used both $X-Z$ and $X-Y$ plane stacking to image TNT-like structures passing through the transwell filter after $48 \mathrm{~h}$ of culture (Fig. 2a and b). Composite 3D images were constructed using Nikon AR software. To assess differences between cell diameters and pore sizes in the filter and to provide visual demonstration of TNT formation, we imaged the cancer cells overlying the pores and the TNTs traversing the entire span of the $10 \mu \mathrm{m}$ polyester membrane (Fig. 2a). Our images detected a 30:1 ratio of greatest cell diameter to pore size, confirming that the cell bodies were too large to move from the upper chamber to the lower chambers via the pores (i.e. cell diameters of MSTO-211H cells were $\sim 12 \mu \mathrm{m}$, and the pores were $\sim 400 \mathrm{~nm} / 0.4 \mu \mathrm{m}$, accounting for the 30 -fold 


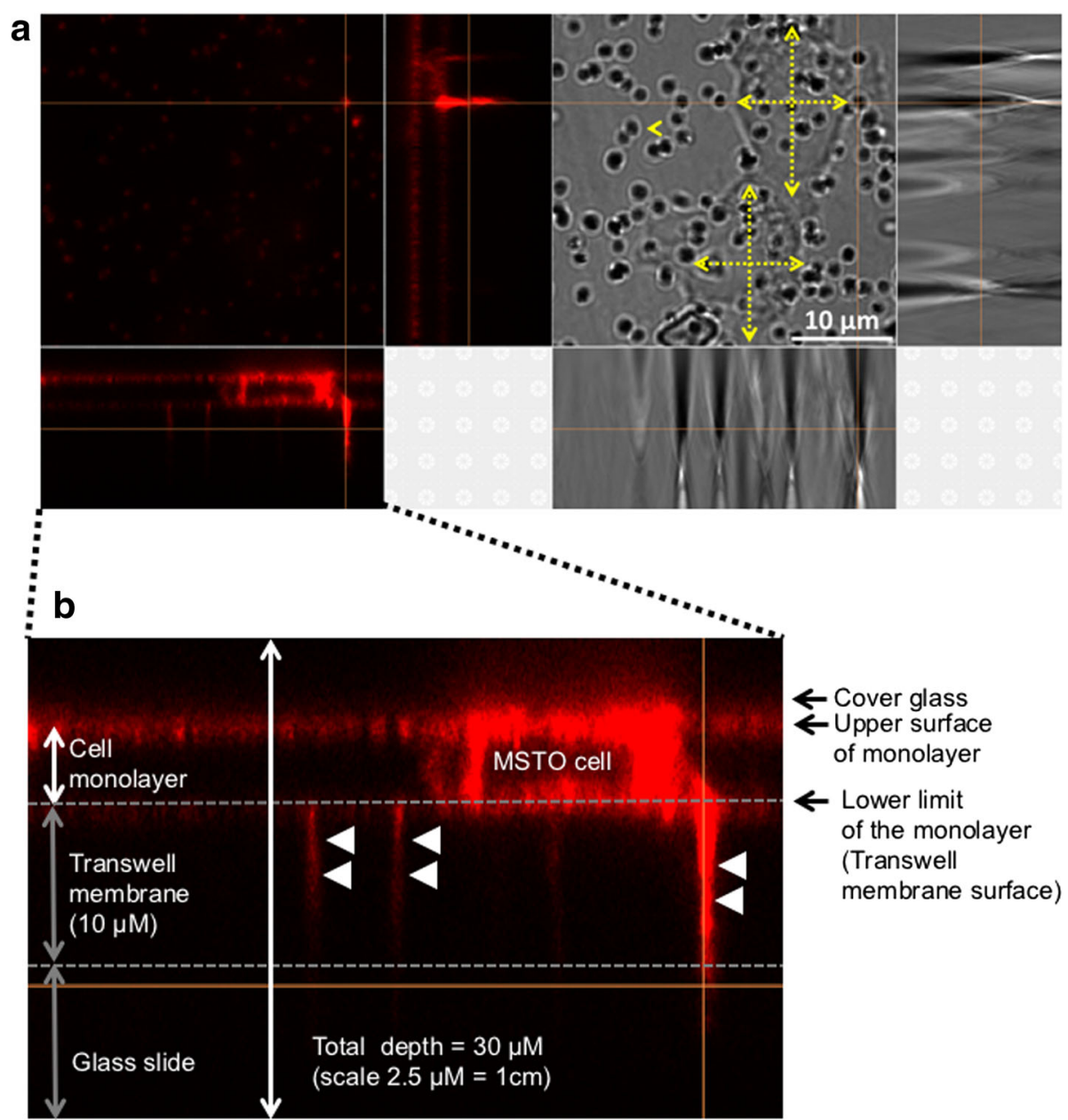

Fig. 2 Confocal microscopy demonstrating TNTs traversing the pores of a transwell polyester membrane filter. MSTO cells were primed in TNT medium (low-serum, hyperglycemic medium) for 7 days prior to plating. To reduce exosomal trafficking, culture medium was removed $24 \mathrm{~h}$ prior to the experiment; cells were washed with PBS, and serum-free medium was added. Cells were stained with Dil prior to placement for culture on the top and bottom filters of a modified Boyden chamber encompassing a polyester filter containing pores measuring $400 \mathrm{~nm}$ in diameter. a Dil-stained cells with TNTs are shown on the left-hand panel. Comparison of MSTO cells and $400 \mathrm{~nm}$ pores is shown in the right-hand panel, with demonstration of Transmitted Detection (TD) imaging. Cells are marked by yellow cross bars and a pore is marked by an arrow head. $\mathbf{b}$ XZ view of Z-stacked confocal images of MSTO cells and associated TNTs/TNT-like structures crossing the membrane filter (indicated by arrowheads)

calculation). This confocal imaging experiment provided supportive evidence that TNTs (or at least TNT-like cellular extensions) can form and protrude through the length of the polyester membrane filter.

\section{Separation of cells using the transwell filter significantly reduces exosome trafficking by at least $66 \%$, when quantified using nanoparticle tracking analysis}

We next quantified differences in exosomal trafficking using the modified transwell assay as compared to open culture. Electron microscopy (EM) is the gold standard for visually identifying exosomes following isolation. They typically measure $\sim 50-200 \mathrm{~nm}$ in diameter, and readily diffuse between cells in open culture. Several studies have demonstrated that physical barriers, such as the membranous filters used in transwell assays, can alone eliminate up to $85 \%$ of exosomal trafficking [20, 24]. Thus, we postulated that additional steps could either eliminate, or nearly eliminate, the remaining $15 \%$ of exosomes and thus prevent the effects of this transfer. The intent of excluding EV trafficking was to ensure that any remaining measures of intercellular transfer could be attributed to TNTs.

Thus, our next step was to confirm the extent by which the transmembrane acted as a physical barrier to prevent EV trafficking of MSTO cells. To accomplish this, an equal number of MSTO cells $\left(0.3 \times 10^{6}\right)$ was added to both the top and bottom chambers of the transwell assay (i.e. onto the membrane filter containing $400 \mathrm{~nm} / 0.4 \mu \mathrm{m}$ pores). In addition, we also added a 
predetermined number $\left(2 \times 10^{9}\right)$ of exosomes (validated by Nanoparticle Tracking Analysis) to the cells in the top transwell chamber. After a 48-h incubation, exosomes isolated from the lower well were imaged to determine how many had passed through the porous membrane filter. As a positive control, a known number of exosomes $\left(2 \times 10^{9}\right)$ were added directly to 6 -well open cultures with MSTO cells and incubated for $48 \mathrm{~h}$. Both experiments were carried out in serum-free mTeSR1 basal medium to ensure that exogenous exosomes were not added. Exosome fractions were isolated from open culture and the bottom transwell chamber, visualized by EM, and counted for comparison. Using this method, we determined that there were significantly fewer exosomes $(80 \%)$ in the bottom transwell chamber than in open culture $(P$ value $<0.005)$ (Fig. 3b, lower-left).
For more details on the experimental approach, please see the Materials and Methods section.

We employed nanoparticle tracking analysis (NTA) to more accurately quantify exosomes and MVs in our studies [35-37]. NTA is a highly sensitive method that utilizes the phenomenon that diffusivity of nanoparticles by Brownian motion in a liquid suspension is determined by size, temperature, and viscosity of the liquid in which they are contained. For this study, we used NTA to assess exosome concentrations more accurately than could be achieved using EM alone. Particles undergoing Brownian motion were digitally recorded; and their speed of motion was subjected to software-based analysis to determine the particle count and size. These findings demonstrated that the use of a porous filter containing the smallest pore sizes $(400 \mathrm{~nm})$ decreased a

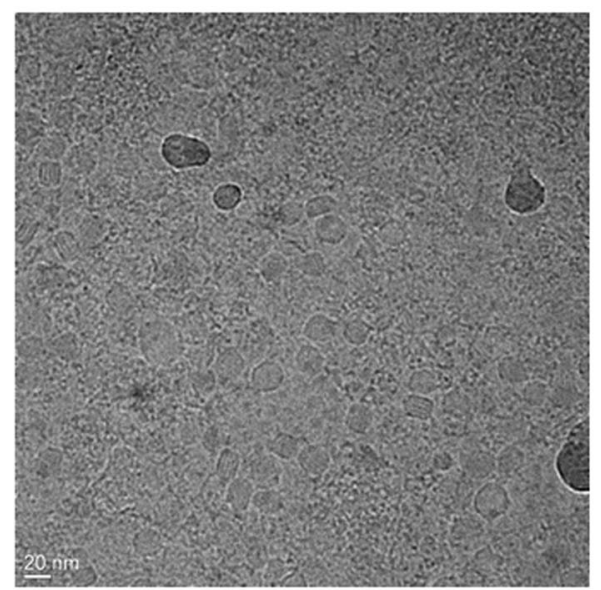

b

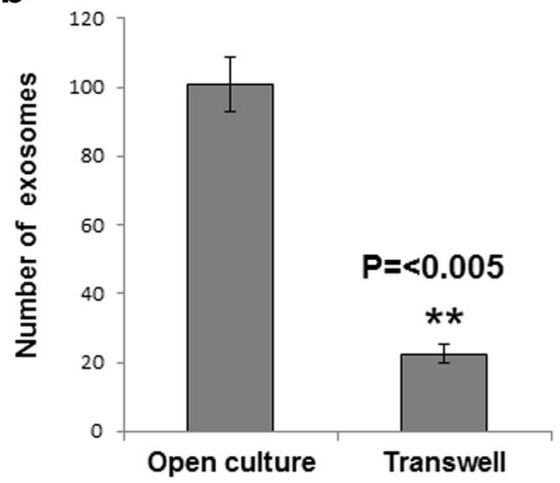

Transwell

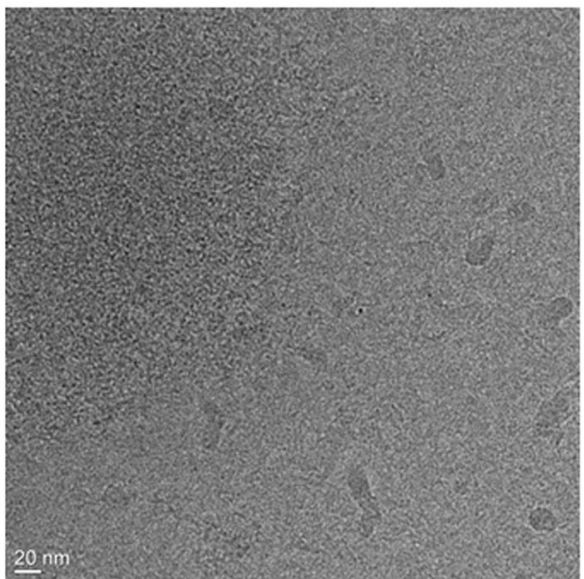

C

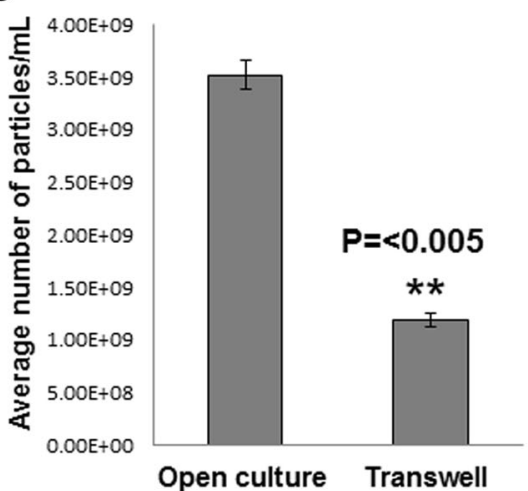

Fig. 3 Transwell polyester membrane filters containing $400 \mathrm{~nm}$-sized pores form a physical barrier that significantly reduces transfer of exosomes in the transwell assay. a Cryo-transmission electron microscopic (TEM) examination of exosomal transfer across a transwell assay membrane filter. TEM was performed on exosomes isolated in open culture wells (positive control, left) and the bottom transwell chamber (right) after $48 \mathrm{~h}$ of culture in serum-free media using the modifications described. $\mathbf{b}$ Quantification of exosomes transmitted to the bottom well of transwell chamber experiments, compared to exosomes in the open culture control. Exosomes were counted from 3 representative images per experiment and averaged. The relative reduction of exosomal trafficking using this transwell filter was $\sim 80 \%$, when assessed by using this method. c Nanoparticle tracking analysis of exosomes from above mentioned transwell and open culture experiments, quantifying the relative reduction at $66 \%$. For statistical analysis, Student's t-test was conducted, with a $p$-value of $\leq 0.05$ 
trafficking of exosomes by 66\% (Fig. 3c, lower-right) ( $p$-value $<0.005)$. Specifically, as depicted in this figure, the average number of exosome particles/ml quantified from open culture was $3.52 \times 10^{9}$, whereas the number of particles $/ \mathrm{ml}$ detected in our transwell system was $1.19 \times 10^{9}$. The percent difference was a $66.2 \%$ reduction: $\left[\left(3.52 \times 10^{9}-1.19 \times 10^{9}\right) / 3.52 \times 10^{9}\right]=0.662$. We noted that that this reduction was less than the $80 \%$ reduction we calculated by assessment using the less specific method of quantifying cryoEM-visualized exosomes. The more specific method of NTA provided a more feasible and likely more accurate platform for quantifying exosomes in this set of experiments.

Having used NTA to confirm that the porous membrane filter significantly reduced exosomal trafficking, we next sought to exclude any trafficking or effects of the remaining $20 \%$ of EVs. To do this, we cultured cells in conditions designed to reduce effects of exosome contamination, secretion, and uptake prior to the transwell assay. We washed MTSO cells and then added culture medium containing exosome-depleted serum. MTSO cells cultured in "restrictive" conditions (i.e. with the stated modifications) or usual passage media (10\% FBS at $37{ }^{\circ} \mathrm{C}$ ) were added to the top chamber of separate transwell plates. Cells were then incubated for $48 \mathrm{~h}$ prior to isolating exosomes that passed through the membrane filter (400 nm-sized pores) into the lower well of the transwell chambers. We then again used NTA to quantify the concentration of exosomes. We found that a greater concentration of EVs was detected among cells cultured in usual passage medium (Fig. 4a) than among cells cultured under modified "restrictive conditions" (Fig. 4b). Specifically, comparison of the NTA profiles revealed that the use of exosome-restrictive conditions independently decreased overall exosomal carryover by $\sim 74 \%$ (i.e. in addition to the $66 \%$ reduction already seen by using the transwell membrane filter) (Fig. 4c). Specifically, as depicted in this figure, the average number of exosome particles $/ \mathrm{ml}$ quantified from normal culture medium was $4.00 \times 10^{9}$, whereas the number of particles $/ \mathrm{ml}$ detected in our restrictive conditions was $1.06 \times 10^{9}$. This percent difference was a $\sim 73.5 \%$ reduction (rounded up to $74 \%$ ): $\left[\left(4.00 \times 10^{9}-1.06 \times 10^{9}\right) /\right.$ $\left.4.00 \times 10^{9}\right]=0.735$. From these data, we determined that a $74 \%$ reduction of EVs not eliminated by the membrane filter alone resulted in a net, or overall, reduction in EV trafficking of $95 \%[(66 \%+(74 \%$ of $20 \%))=0.8+0.148=0.948$ (rounded up to $95 \%)]$. From these data, we concluded that the addition of the specified steps to modify the standard transwell chamber system allowed us to eliminate $95 \%$ of all EV trafficking between cells separated by the filter, thus allowing for more selective communication to take place via an alternate route, TNTs.
As a quality measure of our experimental approach in exosome recovery, we confirmed that our technique was accurate and effective. To accomplish this, we added a known amount of exosomes $\left(2 \times 10^{9}\right)$ determined by NTA to 6-well plates containing no cells. We collected the media after $48 \mathrm{~h}$, isolated the exosomes, and quantitated the EVs by NTA. The efficiency of exosome recovery was $~ 94 \%$, thus providing assurance that our technique of exosome recovery was sufficient (Additional file 3: Figure S3).

\section{Assessment of trafficking of exogenously added exosomes: The transwell polyester membrane containing $400 \mathrm{~nm}$-sized pores serves as an effective physical barrier to exosomal trafficking as compared to open culture without barriers separating cells}

The use of NTA was straightforward and allowed us to quantify EVs with greater accuracy than by using visual inspection and counting via EM. Thus, repeat studies were carried out to more accurately assess the ability of the membrane filter to reduce EV trafficking. We next carried out additional experiments using either open cultures or transwell chambers under the modified 'restrictive conditions'. We added exosomes to MSTO cells, incubated them for $48 \mathrm{~h}$, then recovered exosomes and analyzed them using NTA (Fig. 5a showing data for open culture; and Fig. 5b showing data for modified the transwell approach). Comparison of these two profiles revealed that the media recovered from the transwell chamber in which exosomes were separated by a physical barrier contained significantly fewer exosomes (a $70 \%$ reduction) (Fig. 5c).

\section{Pharmacologic blockade of EV uptake by putative recipient cells: A final step to preventing downstream effects of EV trafficking}

We hypothesized that the final step in preventing EVmediated intercellular communication would be to block exosomal uptake by recipient cells in the lower transwell chamber. Thus, we selected heparin as a pharmacologic inhibitor of exosomal uptake, again using a membrane filter containing $400 \mathrm{~nm}$-sized pores and restrictive culture conditions. Heparin has been shown to be effective at reducing exosome uptake at a concentration of $10 \mu \mathrm{g} / \mathrm{ml}$ $[31,38-40]$. MSTO cells were pre-treated at this dose for 30 min per prior protocols $[31,38,40]$ before being washed and added to the lower transwell chamber. MTSO cells and VAMT mesothelioma-derived exosomes stained with red fluorescing PKH26 dye were added to the top transwell chamber for a 15-min incubation; cells were then washed in order to remove any remaining unbound or free-floating exosomes. After $24 \mathrm{~h}$ of incubation, we used fluorescence microscopy to determine the amount of exosome uptake in recipient cells in the lower chamber that were treated with heparin; these results were compared to 

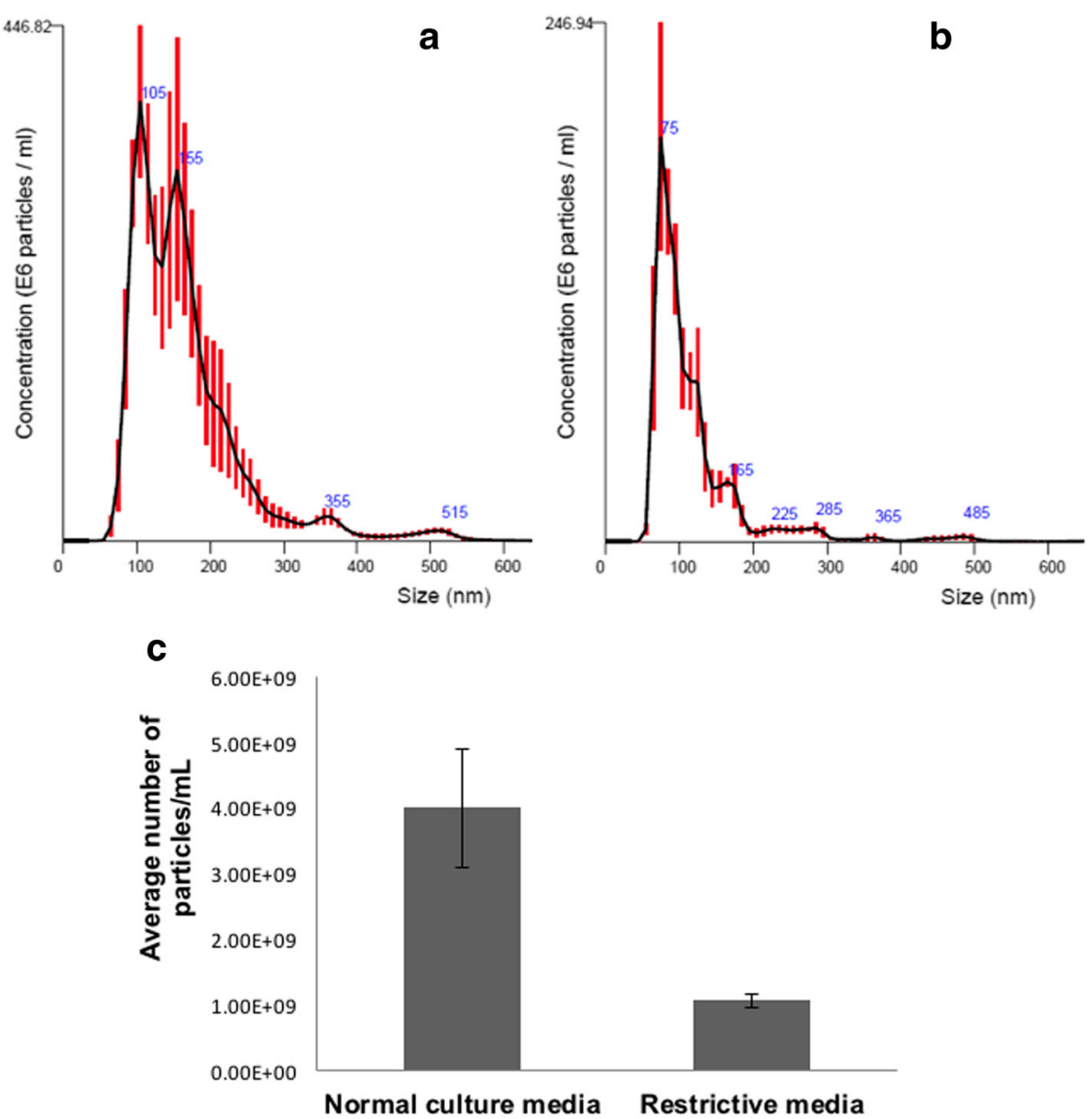

Fig. 4 Modifications to culture conditions can further reduce exosome carryover to the lower transwell chamber, beyond the physical barrier provided by the transmembrane filter. "Restrictive media" conditions refer to washing cells and adding basal, serum-free (mTeSR) medium to avoid addition of exogenous serum-based exosomes. Nanoparticle Tracking Analysis (NTA) was used to determine the concentration of exosomes isolated following usual culture and passage conditions (a) as compared to concentration of exosomes isolated from cells subjected to restrictive medium conditions $(\mathbf{b})$. Mean values from 5 independent runs are shown \pm SD. The restrictive conditions reduced exosome contamination by $\sim 75 \%$ compared to cells in normal culture medium conditions (c)

cells that had not been pretreated with heparin (Fig. 6a; Additional file 4: Figure S4). Fluorescence microscopy images were analyzed using Image J by determining the Corrected Total Cell Fluorescence (CTCF), and divided by cell area to calculate CTCF/ area, a technique that we have reported previously [30]. Heparin treatment of cells in the lower chamber reduced the CTCF/area by $76.5 \%$ as compared to non heparin-treated cells [(control 0.098 - heparin 0.023)/ $0.098=0.765=76.5 \%$ decrease; $p$-value $=0.04$ ] (Fig. 6b) . Although CTCF/area is not an exact surrogate for quantification of EVs, this significant decrease supports the notion that pharmacologic blockade with heparin likely blocks nearly all of the remaining $5 \%$ of EVs that remain following the use of each of the prior steps we have outlined.

\section{Scanning electron microscopy demonstrates TNT-like} structures extending through the $400 \mathrm{~nm}$ pores

The transwell membrane apparatus has been extensively used to assess invasive capacity and migration of cancer cells. The finding of long membrane extensions penetrating from cells cultured in a top chamber toward the bottom chamber through a $1000 \mathrm{~nm}$ pore size filter has been reported using HCT-116 colon cancer cells [41]. To address the issue of whether TNTs can penetrate through the transwell membrane of $400 \mathrm{~nm}$, we preconditioned (primed) MSTO cells in TNT media for a week and plated them onto transwell inserts containing polyester membranes with $400 \mathrm{~nm}$ pores. After $48 \mathrm{~h}$, the membranes were removed, washed, and fixed with $4 \%$ PFA; and the filters mounted onto a scanning electron microscopy (SEM) stage, thereby exposing the bottom 

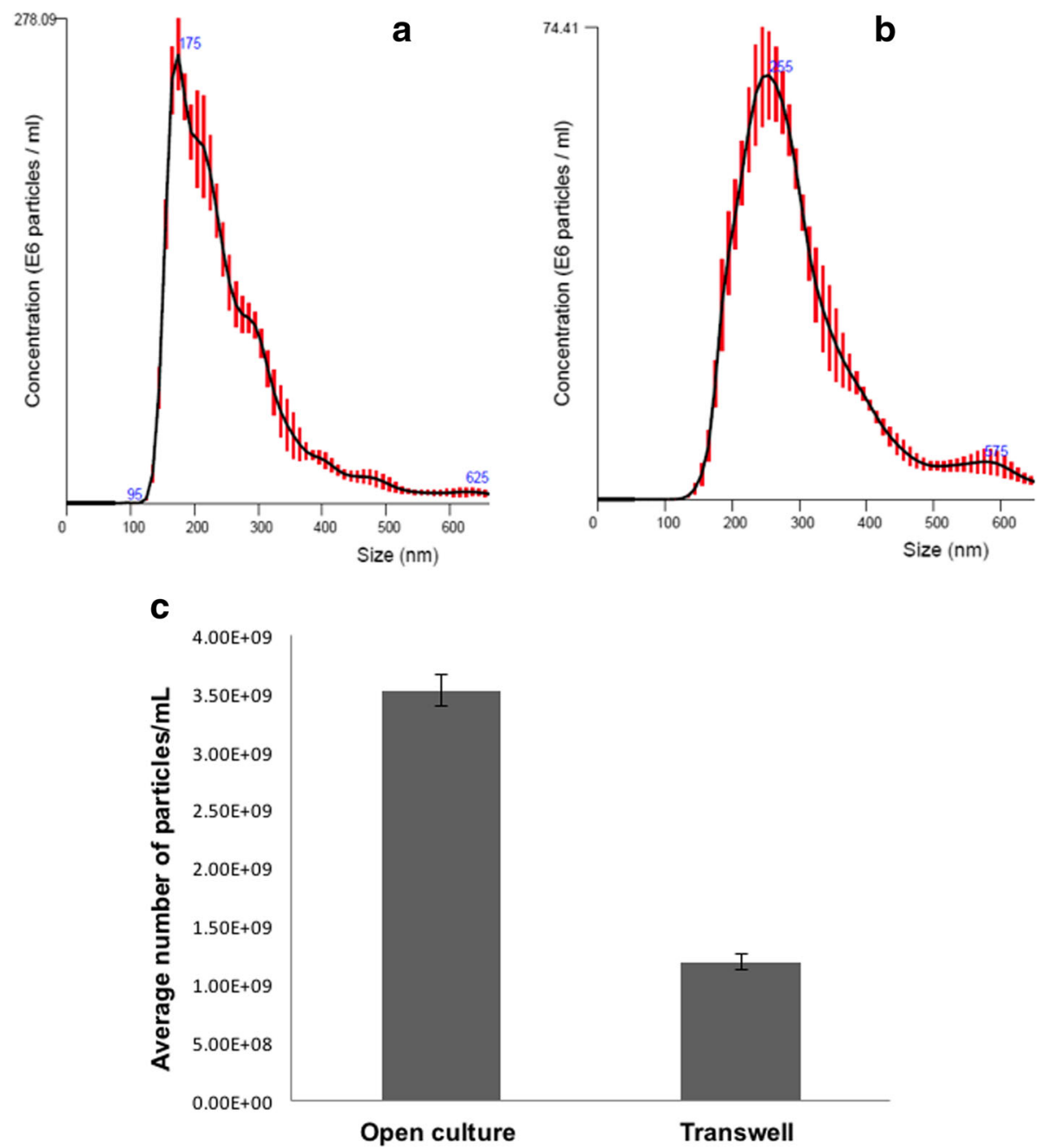

Fig. 5 Assessment of trafficking of exogenously added exosomes: the transwell polyester membrane containing $400 \mathrm{~nm}$-sized pores serves as an effective physical barrier to exosomal trafficking as compared to open culture without barriers separating cells. MSTO cells were prepared under restrictive conditions (using exosome-depleted serum); and then plated and incubated with exogenously added VAMT-derived exosomes $\left(2 \times 10^{9}\right)$ in triplicate for $48 \mathrm{~h}$. After incubation, medium from the bottom chamber was collected and subjected to exosome isolation and NTA as explained in the Methods section. NTA-assessed exosome concentrations (reported as number of particles $/ \mathrm{ml} \times 10^{6}$ ) after open culture in 6-well plates (a); and after culture in the Boyden chamber transwell experiments (b). In the latter experiment, VAMT-derived exosomes were added to the top of the transwell chamber, and medium was recovered after $48 \mathrm{~h}$ from the lower chamber for NTA. The transwell filter with $400 \mathrm{~nm}$ pore size can significantly block exosome transfer, independently of other steps (c). Mean values from 5 independent runs are shown \pm SD

side of the membrane for imaging. Imaging revealed TNTs penetrating through the $400 \mathrm{~nm}$ pores and penetrating the opposite side (Fig. 7). Quite interestingly, we also observed several TNTs that appeared to have fractured in the fixation process, revealing the interior of TNTs exposed in cross-section (Fig. 7 and Additional file 5: Figure S5).

\section{An example of how this assay can be used to assess TNT-selective intercellular communication}

Our group recently reported the use of this modified transwell method for assessing TNT-mediated bystander effect following oncolytic viral infection [33]. In that study, the transwell membrane acted as a physical barrier that eliminated gap junction-mediated cell-to-cell spread of a viral thymidine-kinase activated nucleoside analog compound (ganciclovir) that is often used to study the bystander effect. Use of the actin-destabilizing agent Cytochalasin B, which prevents and disrupts TNT formation, abrogated the bystander effect in this in vitro system, providing further support for the utility of this modified assay.

\section{Discussion}

In our studies of cancer TNTs, we have modified standard commercially-available transwell assays and adapted 

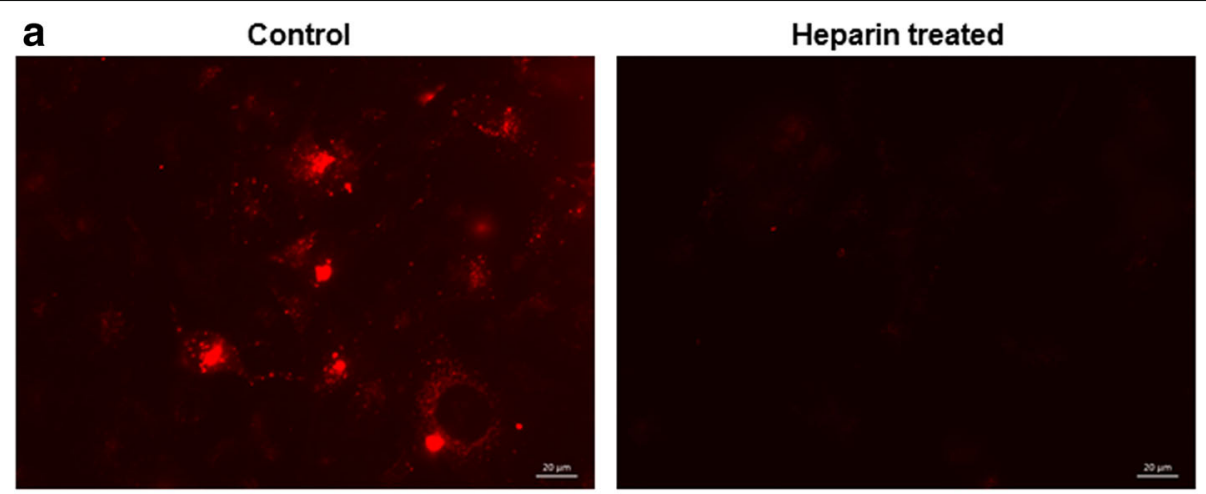

\section{b}

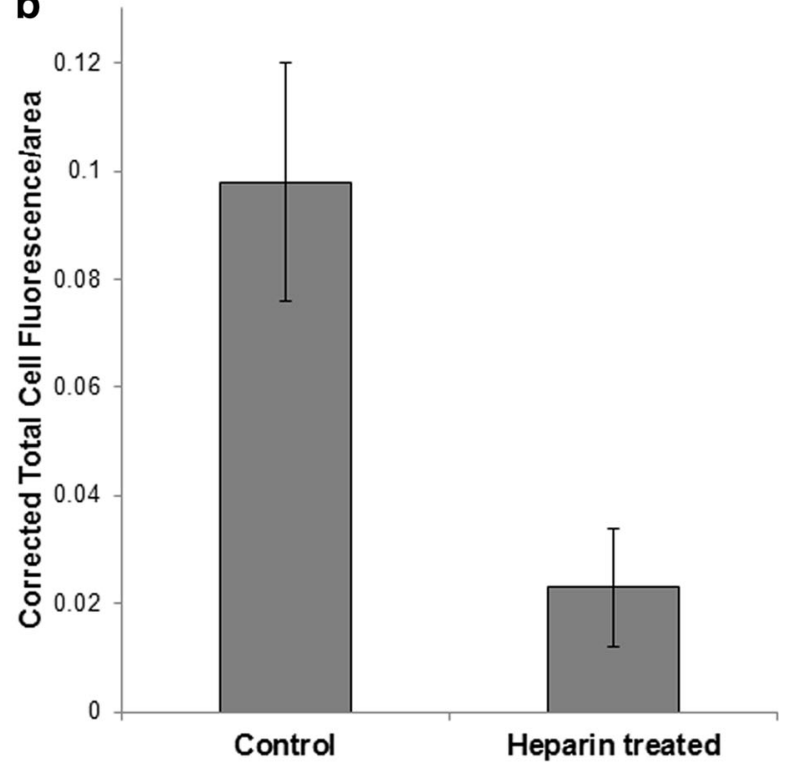

Fig. 6 Exosome uptake is effectively blocked by pharmacologic treatment with heparin. a PKH26 (red dye)-labeled VAMT-derived exosomes were added to MSTO cells on the top of the transwell/Boyden chamber; and to the lower chamber, we added MSTO cells pre-treated with or without $10 \mu \mathrm{g} / \mathrm{mL}$ heparin. Extent of exosomal uptake of cells in the lower chamber was analyzed after $24 \mathrm{~h}$ for both conditions (scale bar $=20 \mu \mathrm{m}$ ). The reduction in red fluorescence in heparin pre-treated cells indicates efficient blocking of exosome uptake. $\mathbf{b}$ This experiment was performed in triplicate; representative images were taken from each replicate and subsequently used for calculations to compare the Corrected Total Cell Fluorescence (CTCF) per area of the control and heparin-treated cells. CTCF/area was calculated for 36 cells in the control group, and 72 cells in the heparin-treated group, and the results were averaged. Our results demonstrate that heparin treatment of recipient cells can significantly block uptake of the majority of remaining exosomes. Mean values are shown with \pm standard error. $p$-value $=0.04$

additional experimental protocols to minimize contamination by exosomes, microvesicles, and microparticles. First, our prior work demonstrated that "priming" cells using low-serum, hyperglycemic medium ("TNT medium") stimulated and quantitatively increased TNT formation, promoted in vivo tumor growth, and altered transcription of key regulatory factors [42]. We therefore primed cells for up to 7 days in TNT medium to increase the likelihood of TNT formation. Second, to decrease the number of exosomes added to the top well at the beginning of experiments, culture medium was removed $24 \mathrm{~h}$ prior to the experiment; cells were washed with PBS, and serum-free medium was added. We used mTeSR1 minimal medium that contained bovine pituitary extract and epidermal growth factor (EGF), but no serum. Third, we used a membrane filter with the smallest commercially available pore size $(400 \mathrm{~nm})$ to ensure that it not only served as an effective barrier to cellular mobility, but also as a conduit for TNT formation. In addition, we used confocal microscopy to image cells overlying the membrane in the top chamber and confirmed that the cell diameter of a malignant cell line (MSTO-211H) was $~ 12 \mu \mathrm{m}$ (i.e. 30 times larger than the diameter of individual $400 \mathrm{~nm}$ pores). Fourth, to mitigate potential effects of exosomal uptake by recipient cells in the bottom chamber, we used pharmacologic agents that are known to prevent this uptake. Examples of such agents include heparin, GW869 (a sphingomyelinase inhibitor), ammonium chloride, and chloroquine [25, 38-40, 43]. For the 


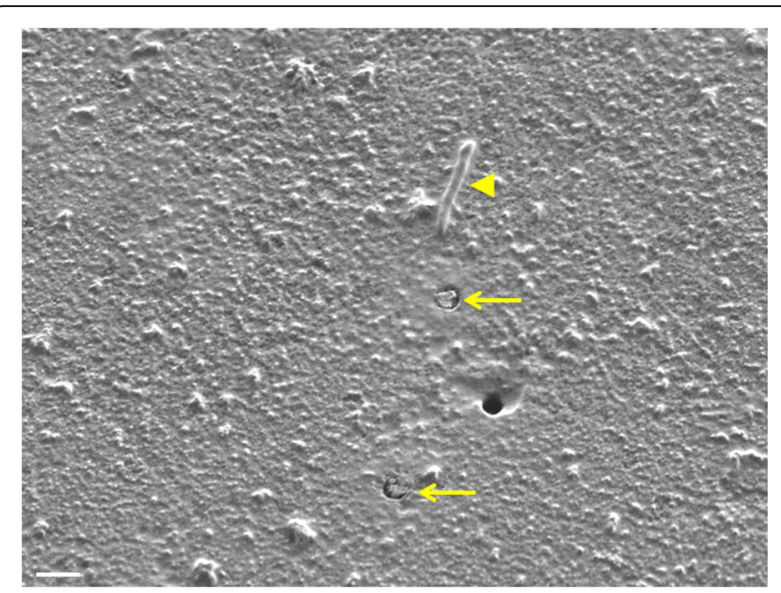

Fig. 7 Scanning Electron Micrograph (SEM) of TNT-like structures penetrating the $400 \mathrm{~nm}$ pores of the transwell membrane. MSTO cells were grown on the transwell membrane culture inserts for $48 \mathrm{~h}$ and then fixed using PFA. On the bottom of the membrane, TNT-like structures were identified and imaged without staining. The image provides evidence that TNTs have the capacity to penetrate and traverse the transwell membrane via the $400 \mathrm{~nm}$-sized pores of the polyester filter (scale bar $1000 \mathrm{~nm}$ ). that formed through the membrane pores, and extended beyond the membrane are shown, marked by arrowheads. Several TNTs were disrupted by the fixation process, but are shown in cross-section (arrows)

present study, we opted to use heparin to prevent exosome uptake by recipient cells in the bottom chamber of the assay due to supportive evidence in the literature, as well as its widespread commercial availability. Our data validated this cumulative series of modifications for studying TNTspecific communication in a transwell assay.

Many studies in the field of intercellular communication have largely focused on identification of the actual cargo rather than specifying the exact intercellular route, or routes, of transport. To accurately determine the role of TNTs in cellular communication, it will be critical to accurately assess TNT-specific transport as compared to intercellular transport occurring via other means. Cells in immediate proximity are most likely to communicate via gap junctions. Long-distance communication in vitro can occur via diffusible lipophilic carriers (e.g. exosomes, MVs). The presence of EVs can potentially confound experiments designed to investigate the effects of TNTspecific intercellular transfer of cargo. For this reason, validated assays are needed to differentiate the effects of TNT-mediated transfer from transfer occurring via EVs.

To date, there has been no assay universally used to confirm TNT-specific transport. The assay most commonly described in the literature is the classic transwell assay, in which a porous membrane filter is used to separate two populations of cells. The membrane filter in most commercially available transwell assays measures $10 \mu \mathrm{m}$ in thickness, thus obstructing cell-to-cell contact and subsequent transfer via gap junctions. At least two studies have demonstrated that use of a transwell assay can reduce exosomal traffic (ie, contact-independent) communication by nearly $85 \%$ [20, 24]; however, in other studies, a similar transwell system has been used with the intention of examining exosome-specific communication [25]. We believe that previous protocols can be consolidated but do need to be reviewed critically to ensure that the experimental approaches are adequate for addressing questions at hand. The transwell assay/Boyden chamber system has been variably used as a negative control. This concept presumed, however, that the porous membrane filter would wholly prevent TNT formation and cargo transfer, or as a means to in fact demonstrate TNT-mediated communication but without exclusion of EV (Summarized in Tables 1 and 2). In addition to transwell assays, open co-culture approaches followed by cell sorting have been used to present claims of cell-cell transfer in cells shown separately to form TNTs; however, this experimental approach cannot discriminate TNT-mediated transfer from other forms of cargo transfer, including gap junctions, EV, and free-floating cargo in culture media. In our current study, we used confocal imaging to demonstrate that TNTs (or TNTlike protrusions) can in fact form effectively in the context of a transwell chamber, and that validated measures can be taken to markedly eliminate EV trafficking, which would otherwise confound TNT-communication specific studies.

Our studies confirm findings from other researchers that a transwell membrane filter can serve as an effective physical barrier to reduce EV trafficking. However, we also considered that the same membrane would likely reduce TNT formation at least to some extent. Nonetheless, while the overall number of TNTs might be reduced by this physical barrier, TNTs can, in fact, form by penetrating the barriers through the open nano-sized pores. In a recently published study from our group, we used this modified transwell assay to assess the ability of TNTs to propagate the bystander effect for inducing cytotoxicity in connected cancer cells following infection with an oncolytic herpes simplex virus-1 (HSV-1) [33]. We found that TNTs were in fact able to mediate the bystander effect following addition of a nucleoside analog (ganciclovir) that was activated by HSV-1 viral thymidine kinase, and that propagation of this activated drugs via TNTs led to a synergistic increase in cell death. These results verified that our modifications can be used to assess TNT-specific intercellular communication, and provide one example of they can be used in functional assessments of TNTs.

The steps outlined here represent a modified form of an assay that is widely available commercially, and thus available to any interested researchers. These steps are just one attempt to exclude the influence of non-TNT- 
based communication. The study was designed to establish an "assay of exclusion" that ideally would leave only TNT-mediated communication remaining. We note that, based on prior studies and the current study, that the membrane filter can prevent transfer of up to $85 \%$ of extracellular vesicles. Thus it is also likely that the same filter would severely diminish TNT formation quantitatively. We performed confocal fluorescence microscopy in an effort to confirm visually whether any TNTs could traverse the membrane filter at all despite this porous barrier. Certainly the physical set-up of the assay presented a high level of technical difficulty in carrying this out, but we postulated that the pores could potentially permit formation of at least some TNTs from the cells in the top chamber. While in most studies TNTs are imaged in vitro in the XY plane, our efforts here included $\mathrm{z}$ stacked imaging in the $\mathrm{XZ}$ plane to confront the 3dimensional aspect of the two-chamber vertical transwell apparatus. Our images demonstrated long fluorescent TNT-like structures traversing the filter. We entertained the possibility whether this finding actually represented transmission of light through the $400 \mathrm{~nm}$ pores, rather than actual physical structures. However, we only visualized several of these protrusion-like extensions, whereas there were dozens of pores seen in each visual field (as demonstrated in Fig. 2). We concluded that our confocal microscopy approach would have shown indiscriminate passage of light through the pores had that been the case.

The relatively small number of TNT-like protrusions extending through the membrane, as compared to the high number of membrane pores, when taken in combination with further direct imaging of protrusions via EM extending outward from the undersurface of the membrane (Fig. 7), further supports the notion that these are TNT-like structures. Interestingly, in addition to visualizing intact protrusions using this EM technique, we did observe several protrusion-like extensions that appeared to have "broken off" during the fixation and handling process. We speculate that this finding provides a glimpse at the interior of TNTs through a cross-sectional view. For comparison, an open filter pore (seen in the lower right-hand quadrant of Fig. 7) appears black, whereas the two pores indicated by yellow arrows show what appear to be groups of filaments that most likely represent filamentous actin. It is well-established that TNTs are actin-based cellular extensions, and that at times based on whether they are protruding or receding, they also may contain dynamic microtubules. To our knowledge, few groups have been able to image TNTs in cross-section. Mineo et al. provided striking cross-sectional and longitudinal examination of TNTs to effectively demonstrate TNT-mediated transport of exosomes between chronic myelogenous leukemia cells using 3-dimensional reconstruction of confocal images
[44]. In one of our prior studies, scanning EM was able to elucidate TNTs forming between MSTO cells in sagittal/longitudinal section, also suggesting bundling of filaments within TNTs [30]. As the mechanism(s) of TNT formation remains an area of intense study, this accidental finding of cross-sectional views of TNTs using the transwell filters could potentially be harnessed to more clearly define the underlying key structure/function components of TNTs.

We combined several methods with the overarching goal of significantly reducing, if not altogether eliminating, trafficking of exosomes and MVs. We found that NTA was a highly useful and accurate method for assessing exosomal/MV concentration; and thus, we used NTA extensively to quantify relative differences in concentration with or without interventions. EM and fluorescence activated cell sorting (FACS) are the most commonly used tools for exosome analysis. The EM approach has disadvantages, as it can be a time-consuming and labor-intensive process that is further limited by potential for artifacts generated during sample preparation. Furthermore, a potential limitation of FACS is its relative insensitivity for particles less than $500 \mathrm{nM}$ in diameter $[35,45]$; and this is especially true for particles that are less than the anticipated width of 50-200 nm for most exosomes and MVs. More recently, NTA has been suggested as a reliable method of exosome quantification $[35,37]$. In the current study we showed that NTA can be successfully and reliably employed for the analysis of exosomes in routine laboratory situations. Advantages of this technique include rapid and efficient use, and potentially less costly as compared to enzyme-based assays and other imaging methods.

The approach outlined herein, as with any assay, has potential methodological and functional limitations, as discussed. For the field of TNT biology to move forward, a variety of assays will need to be designed and appropriately validated to answer key specific questions, including the question of functional effects of TNT-specific transfer. It is our hope that our efforts will be among many that will be validated and used to study TNTs in the years to come.

\section{Conclusions}

The field of TNT biology and intercellular communication has advanced from an in vitro study to that of in vivo relevance to human diseases. TNTs are actively being investigated for their potential role in a number of human diseases, including cancer, blood-based disorders, neurologic and inflammatory diseases. TNTs are a natural biologic conduit for intercellular signaling and transport of cellular cargo. Recent advances in understanding the function and mechanism(s) of TNTs challenge the paradigm that gap junctions, exosomes, or cytokines, and other 
diffusible chemical signals are exclusive modes by which cells communicate. Thus, the method described here for evaluating TNTs can be applied to improve our understanding of their role in multiple physiologic processes and types of disease. As the nascent field continues to grow, validated assays for studying TNT function and effects in vitro will be critical for differentiating this form of cellular transport from other modes of communication.

\section{Additional files}

Additional file 1: Figure S1. Schematic diagram of the transwell experiment. Dil-stained cells were placed on the polyester membrane on the transwell insert and allowed to incubate to permit TNT formation, as described in the Methods section. (TIFF $1454 \mathrm{~kb}$ )

Additional file 2: Figure S2. 3-dimensional confocal fluorescent imaging demonstrates TNTS/TNT-like extensions forming and protruding through the porous transmembrane filter. A portion of the polyester membrane along with cells was cut from the transwell, mounted on a glass slide with a cover glass, and analyzed by confocal microscopy. (TIFF $1375 \mathrm{~kb}$ )

Additional file 3: Figure S3. Validation of exosome recovery. VAMT exosomes $\left(2 \times 10^{9}\right)$ were added into 6 - well plates containing $2 \mathrm{ml}$ of serum free basal mTeSR1 medium and incubated for $48 \mathrm{~h}$. After $48 \mathrm{~h}$, medium was collected and subjected to exosome isolation for NTA. Almost all of the $2 \times 10^{9}$ exosomes added were recovered without a significant loss, with a recovery efficiency of $>95 \%$. The exosome samples were run 5 times and averaged. SD is shown as the error bar. (TIFF $1107 \mathrm{~kb}$ )

Additional file 4: Figure S4. Uptake of exosomes crossing the transwell membrane is significantly decreased by heparin treatment of recipient cells. PKH26 (Red) labelled VAMT exosomes were added to MSTO cells pre-treated with (b) or without (a) $10 \mu \mathrm{g} / \mathrm{mL}$ heparin. Exosome uptake was analyzed after $24 \mathrm{~h}$ of culture. DIC and DIC + fluorescent merged images of control and heparin-treated cells are shown. (TIFF $2404 \mathrm{~kb}$ )

Additional file 5: Figure S5. Scanning Electron Micrograph (SEM) of TNT-like protrusions emerging on the other side of the transwell membrane. This image provides supporting evidence that TNTs have the capacity to penetrate the pores of the transwell membrane. We also noted the presence of broken TNTs in the pores exposing them in cross-section; we postulate that this occurred due to the structurally sensitive nature of TNTs and to the high negative pressure during SEM imaging. Broken TNTs are marked by arrows. (TIFF $2554 \mathrm{~kb}$ )

\section{Abbreviations}

CTCF: Corrected total cell fluorescence; EM: Electron microscopy; EV: Extracellular vesicles; FACS: Fluorescence activated cell sorting; MV: microvesicles; nm: nanometers; NTA: Nanoparticle tracking analysis; PBS: Phosphate buffered saline; TEM: Transmission electron microscopy; TNTs: tunneling nanotubes; $\mu \mathrm{m}$ : microns

\section{Acknowledgements}

We thank Michael Franklin, M.S. for excellent editorial assistance and critical review of the manuscript, and Rachel Vogel, Ph.D for helpful assistance with statistical analysis; and Lihua Li, Ph.D, Snider Desir, Tim Starr, Ph.D, and Martina Bazzaro, Ph.D for technical and analysis assistance. We are grateful to Katia Manova-Todorova, Ph.D, and Sho Fujisawa, Ph.D of the Molecular Cytology Core Facility at Memorial Sloan-Kettering Cancer Center for helpful discussion regarding confocal imaging microscopy and methods. We also thank Guillermo Marques, Ph.D and Mark Sanders, Ph.D for assistance with confocal microscopy performed at the University Imaging Centers at the University of Minnesota; and also thank James Marti, Ph.D of the University of Minnesota Nano Center for assistance in performing the nanoparticle tracking analysis.

Ethical approval and consent to participate Not applicable.

\section{Funding}

This research was supported to E.L. by the NIH Clinical and Translational Science KL2 Scholar Award 8UL1TR000114. The content is solely the responsibility of the authors and does not necessarily represent the official views of the National Institutes of Health. Additional funding and research support included the following: Institutional Research Grant \#118198-IRG-58001-52-IRG94 from the American Cancer Society; the National Pancreas Foundation; the Mezin-Koats Colon Cancer Research Award; The Randy Shaver Cancer Research and Community Fund; the Litman Family Fund for Cancer Research; the University of Minnesota Deborah E. Powell Center for Women's Health Interdisciplinary Seed Grant support (Grant \#PCWH-2013-002); Minnesota Masonic Charities; Minnesota Medical Foundation/University of Minnesota Foundation; the Masonic Cancer Center and Department of Medicine, Division of Hematology, Oncology and Transplantation, University of Minnesota.

Availability of data and materials

Data will be available upon request to the corresponding author.

\section{Authors' contributions}

$V T, P O, X Z, C J S, S S$, and EL contributed to designing experiments. VT and PW performed the reported experiments. CJS, SS, and EL provided reagents. VT, $\mathrm{PO}$, and XZ performed data analysis. CJS, SS, and EL performed interpretation and drafted the article. All authors contributed to writing and editing the text of the manuscript, and approved of the final manuscript for publication.

\section{Consent for publication}

All authors have reviewed the final manuscript prior to submission and consented to its publication.

\section{Competing interests}

The authors declare that they have no competing interests.

\section{Publisher's Note}

Springer Nature remains neutral with regard to jurisdictional claims in published maps and institutional affiliations.

\section{Author details}

${ }^{1}$ Department of Medicine, Division of Hematology, Oncology and Transplantation, University of Minnesota, Mayo Mail Code 480, 420 Delaware Street SE, Minneapolis, MN 55455, USA. ${ }^{2}$ Department of Surgery, University of Minnesota, Minneapolis, MN 55455, USA. ${ }^{3}$ Department of Medicine, Division of Gastroenterology, Hepatology and Nutrition, University of Minnesota, Minneapolis, MN 55455, USA. ${ }^{4}$ Department of Genetics, Cell Biology and Development, University of Minnesota, Minneapolis, MN 55455, USA.

${ }^{5}$ Graduate Faculty, Department of Integrative Biology and Physiology, University of Minnesota, Minneapolis, MN 55455, USA. 'Present Address: Molecular Diagnostics Laboratory, University of Minnesota Medical Center, Fairview, 420 Delaware St SE, MMC 198, Minneapolis, MN 55455, USA.

Received: 21 September 2017 Accepted: 30 October 2017

Published online: 13 November 2017

\section{References}

1. Biran A, et al. Senescent cells communicate via intercellular protein transfer. Genes Dev. 2015;29:791-802. doi:10.1101/gad.259341.115.

2. Connor $Y$, et al. Physical nanoscale conduit-mediated communication between tumour cells and the endothelium modulates endothelial phenotype. Nat Commun. 2015;6:8671. doi:10.1038/ncomms9671.

3. Costanzo $\mathrm{M}$, et al. Transfer of polyglutamine aggregates in neuronal cells occurs in tunneling nanotubes. J Cell Sci. 2013;126:3678-85. doi:10.1242/jcs.126086.

4. Gousset $\mathrm{K}$, et al. Prions hijack tunnelling nanotubes for intercellular spread. Nat Cell Biol. 2009;11:328-36. doi:10.1038/ncb1841.

5. Langevin C, Gousset K, Costanzo M, Richard-Le Goff O, Zurzolo C. Characterization of the role of dendritic cells in prion transfer to primary neurons. Biochem J. 2010;431:189-98. doi:10.1042/BJ20100698.

6. Martin N, et al. Virological synapse-mediated spread of human immunodeficiency virus type 1 between T cells is sensitive to entry inhibition. J Virol. 2010;84:3516-27. doi:10.1128/JVI.02651-09.

7. Naphade S, et al. Brief reports: Lysosomal cross-correction by hematopoietic stem cell-derived macrophages via tunneling nanotubes. Stem Cells. 2015; 33:301-9. doi:10.1002/stem.1835. 
8. Niu X, Gupta K, Yang JT, Shamblott MJ, Levchenko A. Physical transfer of membrane and cytoplasmic components as a general mechanism of cellcell communication. J Cell Sci. 2009;122:600-10. doi:10.1242/jcs.031427.

9. Pande $\mathrm{S}$, et al. Metabolic cross-feeding via intercellular nanotubes among bacteria. Nat Commun. 2015;6:6238. doi:10.1038/ncomms7238.

10. Pasquier J, et al. Different modalities of intercellular membrane exchanges mediate cell-to-cell p-glycoprotein transfers in MCF-7 breast cancer cells. J Biol Chem. 2012;287:7374-87. doi:10.1074/jbc.M111.312157.

11. Pietila $M$, et al. Mortalin antibody-conjugated quantum dot transfer from human mesenchymal stromal cells to breast cancer cells requires cell-cell interaction. Exp Cell Res. 2013;319:2770-80. doi:10.1016/j.yexcr.2013.07.023.

12. Rechavi O, Goldstein I, Vernitsky H, Rotblat B, Kloog Y. Intercellular transfer of oncogenic H-Ras at the immunological synapse. PLoS One. 2007;2:e1204. doi:10.1371/journal.pone.0001204.

13. Schoelermann J, Burtey A, Allouni ZE, Gerdes HH, Cimpan MR. Contactdependent transfer of TiO2 nanoparticles between mammalian cells. Nanotoxicology. 2016;10:204-15. doi:10.3109/17435390.2015.1048322.

14. Sowinski S, et al. Membrane nanotubes physically connect T cells over long distances presenting a novel route for HIV-1 transmission. Nat Cell Biol. 2008;10:211-9. doi:10.1038/ncb1682.

15. Teague JE, Ryu HY, Kirber M, Sherr DH, Schlezinger JJ. Proximal events in 7,12-dimethylbenz[a]anthracene-induced, stromal cell-dependent bone marrow B cell apoptosis: stromal cell-B cell communication and apoptosis signaling. J Immunol. 2010;185:3369-78. doi:10.4049/jimmunol.0902541.

16. Vallabhaneni KC, Haller H, Dumler I. Vascular Smooth Muscle Cells Initiate Proliferation of Mesenchymal Stem Cells by Mitochondrial Transfer via Tunneling Nanotubes. Stem Cells Dev. 2012;21:3104-13. doi:10.1089/scd. 2011.0691.

17. Zaccard CR, et al. CD40L induces functional tunneling nanotube networks exclusively in dendritic cells programmed by mediators of type 1 immunity. J Immunol. 2015;194:1047-56. doi:10.4049/jimmunol.1401832.

18. Zani BG, Indolfi L, Edelman ER. Tubular bridges for bronchial epithelial cell migration and communication. PLoS One. 2010;5:e8930. doi:10.1371/journal. pone.0008930

19. Zhang $L$, Zhang $Y$. Tunneling nanotubes between rat primary astrocytes and C6 glioma cells alter proliferation potential of glioma cells. Neurosci Bull. 2015;31:371-8. doi:10.1007/s12264-014-1522-4.

20. Zomer A, et al. Exosomes: fit to deliver small RNA. Commun Integr Biol. 2010;3:447-50. doi:10.4161/cib.3.5.12339.

21. Guescini M, et al. Microvesicle and tunneling nanotube mediated intercellular transfer of g-protein coupled receptors in cell cultures. Exp Cell Res. 2012;318:603-13. doi:10.1016/j.yexcr.2012.01.005.

22. $\mathrm{Hu} \mathrm{J}$, et al. An in vitro investigation into the role of bone marrowderived mesenchymal stem cells in the control of disc degeneration. Mol Med Rep. 2015;12:5701-8. doi:10.3892/mmr.2015.4139.

23. Labelle M, Begum S, Hynes RO. Direct signaling between platelets and cancer cells induces an epithelial-mesenchymal-like transition and promotes metastasis. Cancer Cell. 2011;20:576-90. doi:10.1016/j.ccr.2011.09.009.

24. Munoz JL, et al. Delivery of functional anti-miR-9 by Mesenchymal stem cell-derived Exosomes to Glioblastoma Multiforme cells conferred Chemosensitivity. Mol Ther Nucleic Acids. 2013;2:e126. doi:10.1038/mtna. 2013.60 .

25. Umezu T, Ohyashiki K, Kuroda M, Ohyashiki JH. Leukemia cell to endothelial cell communication via exosomal miRNAs. Oncogene. 2013;32:2747-55. doi:10.1038/onc.2012.295.

26. Zhou HL, et al. Intercellular transfer of P-glycoprotein from the drug resistant human bladder cancer cell line BIU-87 does not require cell-to-cell contact. J Urol. 2013;190:1069-75. doi:10.1016/j.juro.2013.04.053.

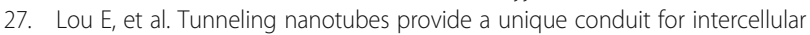
transfer of cellular contents in human malignant pleural mesothelioma. PLoS One. 2012;7:e33093. doi:10.1371/journal.pone.0033093.

28. Thayanithy, V. et al. Tumor exosomes induce tunneling nanotubes in lipid raft-enriched regions of human mesothelioma cells. Exp Cell Res 323, 178-188, doi:10.1016/j.yexcr.2014.01.014 (2014)

29. Thery, C., Amigorena, S., Raposo, G. \& Clayton, A. Isolation and characterization of exosomes from cell culture supernatants and biological fluids. Curr Protoc Cell Biol Chapter 3, Unit 3 22, doi:10.1002/0471143030. cb0322s30 (2006).

30. Thayanithy $V$, et al. Tumor exosomes induce tunneling nanotubes in lipid raft-enriched regions of human mesothelioma cells. Exp Cell Res. 2014;323: 178-88. doi:10.1016/j.yexcr.2014.01.014.
31. Franzen, C. A. et al. Characterization of uptake and internalization of exosomes by bladder cancer cells. Biomed Res Int 2014, 619829, doi:10.1155/2014/619829 (2014).

32. Ady JW, et al. Intercellular communication in malignant pleural mesothelioma: properties of tunneling nanotubes. Front Physiol. 2014:5:400. doi:10.3389/fphys. 2014.00400.

33. Ady J, et al. Tunneling nanotubes: an alternate route for propagation of the bystander effect following oncolytic viral infection. Mol Ther Oncolytics. 2016:3:16029. doi:10.1038/mto.2016.29.

34. Desir $\mathrm{S}$, et al. Tunneling nanotube formation is stimulated by hypoxia in ovarian cancer cells. Oncotarget. 2016; 10.18632/oncotarget.9504.

35. Mehdiani, A. et al. An innovative method for exosome quantification and size measurement. J Vis Exp, 50974, doi:10.3791/50974 (2015).

36. Witwer KW, et al. Standardization of sample collection, isolation and analysis methods in extracellular vesicle research. J Extracell Vesicles. 2013:2 doi:10.3402/jev.v2i0.20360.

37. Hannafon $\mathrm{BN}$, et al. Plasma exosome microRNAs are indicative of breast cancer. Breast Cancer Res. 2016;18:90. doi:10.1186/s13058-016-0753-x.

38. Atai NA, et al. Heparin blocks transfer of extracellular vesicles between donor and recipient cells. J Neuro-Oncol. 2013;115:343-51. doi:10.1007/ s11060-013-1235-y.

39. Christianson HC, Svensson KJ, van Kuppevelt TH, Li JP, Belting M. Cancer cell exosomes depend on cell-surface heparan sulfate proteoglycans for their internalization and functional activity. Proc Natl Acad Sci U S A. 2013;110: 17380-5. doi:10.1073/pnas.1304266110.

40. Osterman CJ, et al. Curcumin modulates pancreatic adenocarcinoma cellderived Exosomal function. PLoS One. 2015;10:e0132845. doi:10.1371/ journal.pone.0132845.

41. Schoumacher M, Goldman RD, Louvard D, Vignjevic DM. Actin, microtubules, and vimentin intermediate filaments cooperate for elongation of invadopodia. J Cell Biol. 2010;189:541-56. doi:10.1083/jcb.200909113.

42. Pasquier J. et al. Preferential transfer of mitochondria from endothelial to cancer cells through tunneling nanotubes modulates chemoresistance. J Transl Med. 2013;11:94. doi:10.1186/1479-5876-11-94.

43. Climent $M$, et al. TGFbeta triggers miR-143/145 transfer from smooth muscle cells to endothelial cells, Thereby Modulating Vessel Stabilization. Circ Res. 2015:116:1753-64. doi:10.1161/CIRCRESAHA.116.305178.

44. Mineo $\mathrm{M}$, et al. Exosomes released by $\mathrm{K} 562$ chronic myeloid leukemia cells promote angiogenesis in a Src-dependent fashion. Angiogenesis. 2012;15: 33-45. doi:10.1007/s10456-011-9241-1.

45. Momen-Heravi F, et al. Alternative methods for characterization of extracellular vesicles. Front Physiol. 2012;3:354. doi:10.3389/fphys.2012.00354.

46. Fruhbeis $C$. et al. Neurotransmitter-triggered transfer of exosomes mediates oligodendrocyte-neuron communication. PLoS Biol. 2013;11:e1001604. doi:10.1371/journal.pbio.1001604

\section{Submit your next manuscript to BioMed Central and we will help you at every step:}

- We accept pre-submission inquiries

- Our selector tool helps you to find the most relevant journal

- We provide round the clock customer support

- Convenient online submission

- Thorough peer review

- Inclusion in PubMed and all major indexing services

- Maximum visibility for your research

Submit your manuscript at www.biomedcentral.com/submit 